Résumés des conférences et travaux

\title{
L'Europe et le monde germanique (époque moderne et contemporaine)
}

Jacques Le Rider

\section{OpenEdition}

\section{Journals}

Édition électronique

URL : https://journals.openedition.org/ashp/3191

DOI : 10.4000/ashp.3191

ISSN : 1969-6310

Éditeur

Publications de l'École Pratique des Hautes Études

\section{Édition imprimée}

Date de publication : 1 septembre 2019

Pagination : 365

ISSN : 0766-0677

\section{Référence électronique}

Jacques Le Rider, «L'Europe et le monde germanique (époque moderne et contemporaine) », Annuaire de l'École pratique des hautes études (EPHE), Section des sciences historiques et philologiques [En ligne],

150 | 2019, mis en ligne le 12 juin 2019, consulté le 06 juillet 2021. URL : http:// journals.openedition.org/ashp/3191; DOI : https://doi.org/10.4000/ashp.3191 


\title{
L'EUROPE ET LE MONDE GERMANIQUE (ÉPOQUE MODERNE ET CONTEMPORAINE)
}

\author{
Directeur d'études : M. Jacques LE RIDER
}

Programme de l'année 2017-2018 : Karl Kraus entre Vienne, Berlin et Prague.

En conclusion d'un cycle de conférences consacrées à Karl Kraus depuis plusieurs années, on a étudié la période qui va de l'automne 1909 à l'été 1914. Celle-ci est marquée d'abord par le retour de Kraus à Berlin et sa collaboration avec la revue Der Sturm de Herwarth Walden, par les premières lectures publiques de Kraus (celles-ci vont devenir le creuset d'une nouvelle communauté intellectuelle), puis par sa rupture avec le milieu berlinois. Accueilli triomphalement à Prague, Kraus se brouille avec Max Brod et Franz Werfel, sous le regard de Kafka. C'est à Innsbruck, à la faveur l'enquête que lui consacre la revue Der Brenner en 1913, que que Karl Kraus reçoit la consécration la plus éclatante.

Durant cette période 1909-1914, Karl Kraus compose son manifeste esthétique « Heine et les conséquences » fondé sur une critique de l'ornement rhétorique dont le genre du feuilletonisme journalistique fait un usage immodéré, critique parallèle à la critique de l'ornement dont l'architecte Adolf Loos fait son cheval de bataille. Attaché à réfuter l'idée de progrès, dans l'ensemble hostile aux avant-gardes, en guerre avec les psychanalystes, Karl Kraus campe sur des positions antimodernes. Sa conversion au catholicisme en avril 1911 et ce qu'il appelle lui-même sa « nostalgie des fréquentations aristocratiques » vont de pair avec sa tendance à l'antisémitisme culturel.

Karl Kraus donne à sa critique des journaux, qui, jusque-là, consistait pour l'essentiel à faire la satire des journalistes et à dénoncer la corruption des industriels de la presse, une portée nouvelle au moment de l'affaire Friedjung. Montrant comment les dirigeants viennois partisans d'une guerre préventive contre la Serbie ont fait paraître dans la presse viennoise, avec la caution de l'historien et journaliste Heinrich Friedjung, de faux documents destinés à répandre dans l'opinion le sentiment que la guerre contre la Serbie est inévitable, Kraus clame que le journalisme représente pour l'Autriche-Hongrie et pour l'Europe une menace beaucoup plus grande et plus réelle que la Serbie. En analysant le pouvoir de construction et de manipulation des journaux à grand tirage, il approfondit et il élargit sa critique des médias. 